\title{
Solar Tracking using Arduino \& Determination of Shading Effect
}

\author{
Harisha Topgi ${ }^{1}$, Omkar Vaze ${ }^{2}$, Ganesh Markad ${ }^{3}$, Omkar Shete ${ }^{4}$ \\ BE Student, Electrical, NBN Sinhgad School of Engineering, Pune, India ${ }^{1,2,3}$ \\ Assistant Professor, Electrical, NBN Sinhgad School of Engineering, Pune, India ${ }^{4}$
}

\begin{abstract}
In today's world, especially in INDIA, need and use of power supply is increasing drastically day by day. The supply of electricity is falling back to the increasing demand of power. Moreover the conventional reserves (i.e., petroleum, coal, gas) and other non-renewable resources are depleting at a faster rate which is now widely recognized. As we know that solar energy is abundant in nature and also is a renewable source of energy. This project focuses on the maximum and efficient use of solar energy by tracking it in real time using arduino software of the single axis solar tracker while still considering the economic factor. The project also involves wind protection scheme along with determination of the effect of shading on the solar panels which is often responsible for considerably reducing the power output from the solar panels. The main components used in this project are Solar Panels, Arduino UNO, Light Detecting Resistors, Hall Effect sensor, Servomotor etc. The aim of this project is to provide maximum and efficient use of Solar Energy at an affordable price.
\end{abstract}

Keywords: LDR, EEPROM, ADC, DC, LCD.

\section{INTRODUCTION}

Since few years, lots of domestic people around the globe are making use of solar energy in their vicinity as an external or backup source. The entire reason behind this is that the solar energy is a never-ending source of energy which can last for a longer period of time by providing not only electricity but also heat energy to the user. In near future, solar energy will prove to be one of the best usable and unlimited means of supplying power. Solar energy can be concentrated using a solar panel and then can be converted to electric power supply. A solar tracker is a self-operating solar panel that literally tracks the movement of sun and harnesses its power. The panels act as conductors, receiving the solar radiation followed by heating and producing power. Until now there have been many developments in the solar tracker. Single axis solar tracker: that tracks the sun only in one direction and dual axis tracker which is capable of tracking the sun in both the directions. Basically, trackers are of two types: active and passive. Active tracker makes use of motors and gears to move the tracker by means of a controller that responds to the sun's path.

In this project, we are making use of Light Dependent Resistors to absorb the radiating energy of the sun which will be given to the controller part which then commands the motor to move the panels to the position with maximum intensity. Also, we are including an additional protection feature in this project to minimize or eliminate the effect of wind (storm) by using a sensor which will give an indication to the controller if the wind speed increases from a prescribed value thus protecting the panels from the damage. The drop in the voltage due to the effect of shading is also indicated on the display and warning the local personnel about the possible interruption and whether if it is temporary or permanent. Above all, the economic factor is been focused upon and an effort has been made to make this project economically affordable for the domestic purpose.

\section{METHOD EMPLOYED}

The following project is sectionalized in 3 stages comprising of an input stage where the input is taken from the two sensors i.e. LDR and Hall Effect sensor. A controller part receives the signal from sensors and gives command and last stage is the driving unit that contains the motor used to position the solar panel. Block diagram of the project is shown below. The concept in this project is: the two output voltages from the two light dependent resistors (LDR) are received by the microcontroller (Arduino ATmega328P) in analog form which is then converted into digital form by the microcontrollers inbuilt analog to digital converter (ADC). After receiving this signal, it analysis the difference between the two voltages and gives command to the driving unit that comprises of a de servomotor which receives this command sent by the microcontroller and adjusts the solar panel at an angle such that the intensity on both the LDRs are equal. A magnet is attached to the blades of a fan along with a Hall Effect sensor, as the wind speed increases the magnet attached to the blades produces high and low pulses which is proportional to the speed which is detected by the 


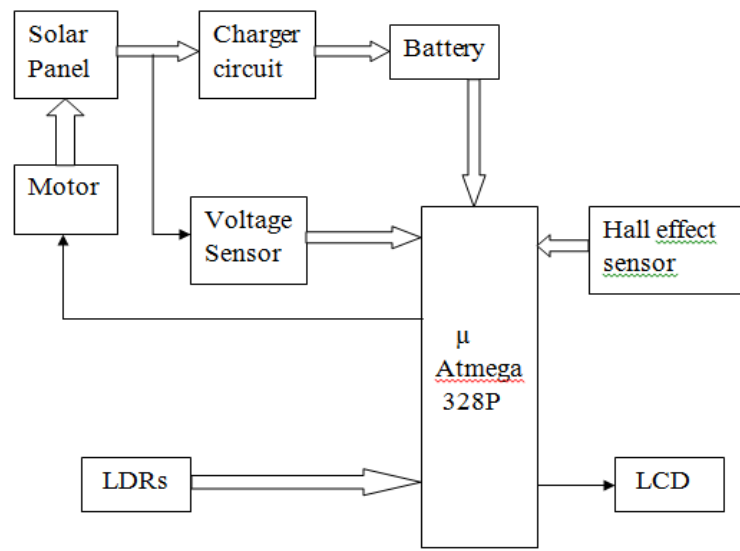

Fig 1: Block Diagram

Hall Effect sensor. The Hall Effect sensor gives this signal to the controller and if the speed of the wind is above the prescribed limit, it commands the servomotor to align the solar panels horizontally i.e. $180^{\circ}$. This is an additional feature included in this project to avoid the damages caused due to unexpected climatic changes for ex. during storms; a high gush of wind may cause the solar panels to fall off, since it may be aligned at a specific angle with respect to the sun's direction making it more vulnerable to the high wind speed. Aligning the solar panels to $180^{\circ}$ will reduce or eliminate this damage as the wind will then flow underneath the solar panel thus nullifying or minimizing the effect. The effect of shading is greatly reflected on the voltage. In other words, shading causes significant drop in the output voltage. This drop in voltage is detected by the voltage sensor and is also indicated on the display which helps the personnel and/or operator in the plant to get an idea whether the interruption is permanent (Leaf) or temporary (Clouds) if found permanent, the operator can physically remove the object by visiting the particular panel, ensuring complete and uninterrupted absorption of sun rays.

\section{PROGRAMMING AND FLOWCHART}

Arduino ATmega328P is used as the controller in this project and has an inbuilt feature of analog to digital converter (ADC). The flowchart of the complete process is given below:

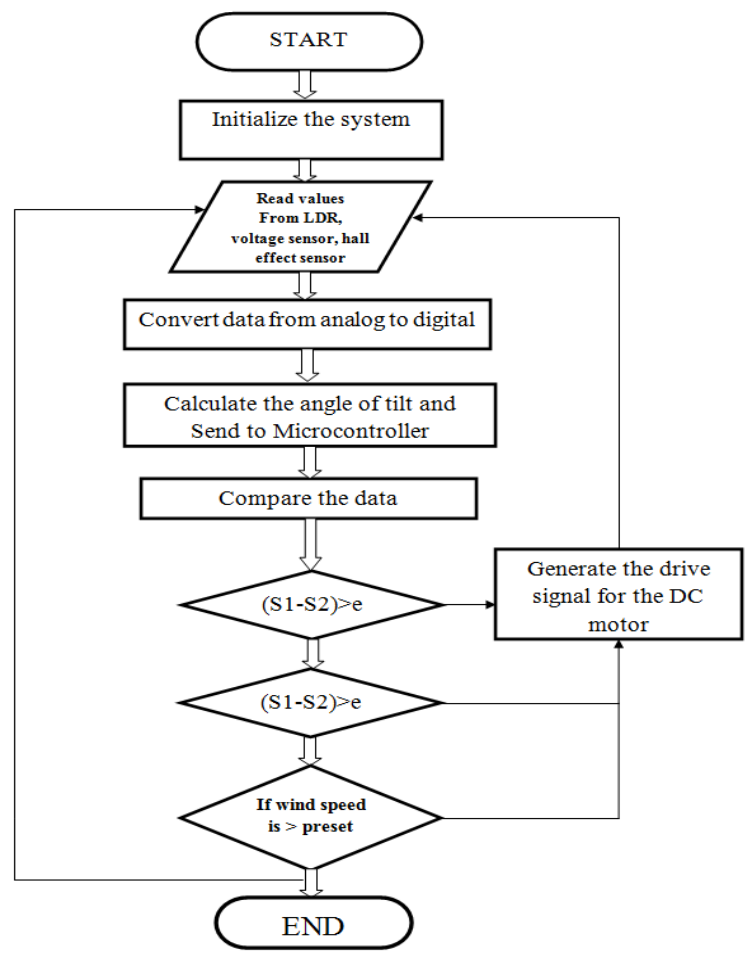

Fig 2: Flowchart 


\section{International Journal of Innovative Research in} Electrical, Electronics, Instrumentation and Control Engineering

\section{ISO 3297:2007 Certified}

Vol. 5, Issue 6, June 2017

A C program is loaded into the controller and the process is performed as per the flowchart given above.

\section{RESULT AND DISCUSSION}

The results of this model were obtained from the outputs of the two panels. An average reading during a bright sunny day from the static panel and tracking panel were obtained for an entire day. The obtained tabulated results clearly show that: the tracking panel as compared to static panel receives more sun rays and provides more output power giving more efficiency comparatively.

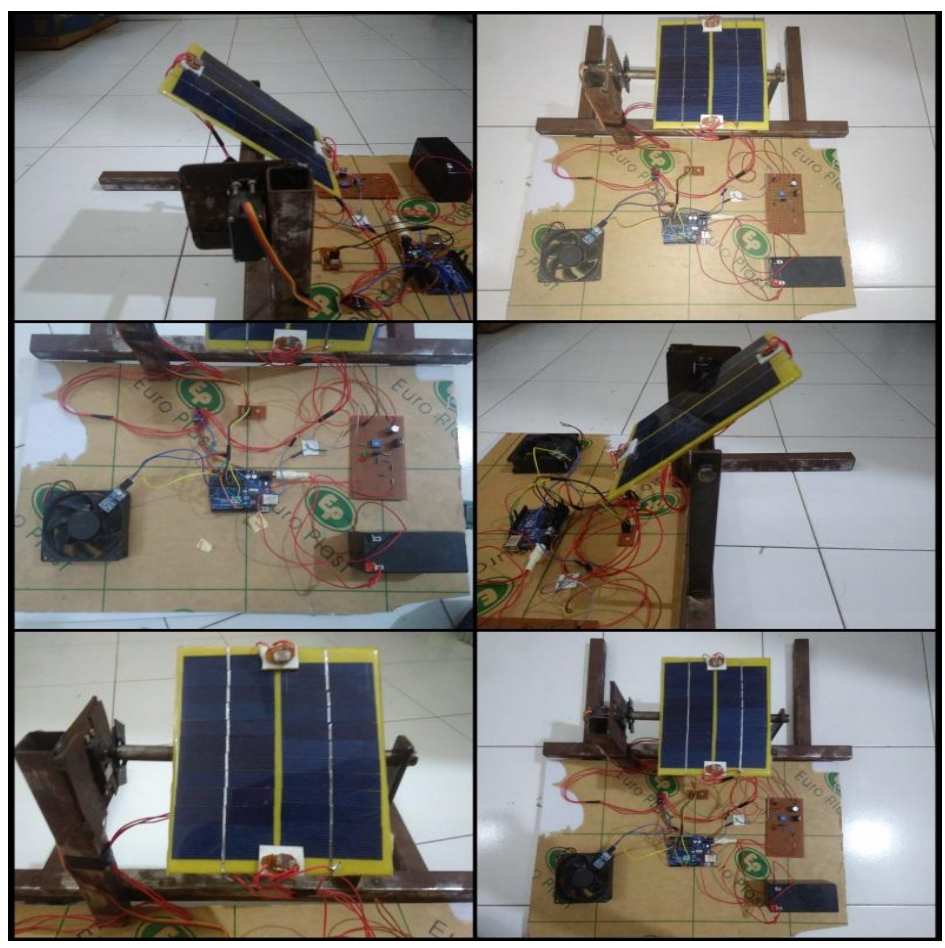

Fig 3: project model

\section{A) Charging Circuit:}

The below fig. shows the schematic of the charging circuit used in the model:

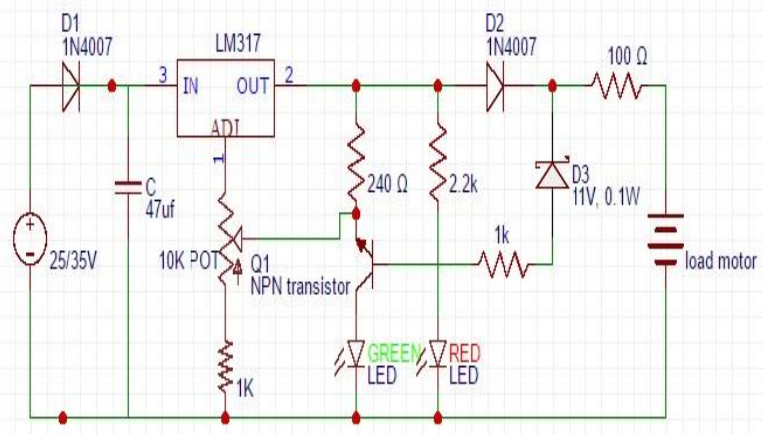

Fig 4: Charging circuit

\section{B) MICROCONTROLLER:}

A code was written in the program for the microcontroller to read the values that have been stored. The ATmega 328P has 1024 bytes of EEPROM. The obtained readings were converted into volts. 5volts has been applied as the Vcc to the microcontroller and the LDRs. The digital values were obtained in the range of 0-1023 after the conversion. The conversion is performed by the equation given below:

LDR Output $=\frac{\text { Equivalent } \text { digital output } * 5}{1023}$ volts 


\section{International Journal of Innovative Research in} Electrical, Electronics, Instrumentation and Control Engineering

\section{ISO 3297:2007 Certified}

Vol. 5, Issue 6, June 2017

Table 1: Output readings from solar panels

\begin{tabular}{|l|l|l|}
\hline Hours & Using static solar panel & Using tracking solar panel \\
\hline$(6: 30 a m-6: 30 p m)$ & Voltage $(\mathbf{V})$ & Voltage $(\mathbf{V})$ \\
\hline $6: 30$ & 16.6 & 17.4 \\
\hline $7: 30$ & 16.9 & 18.6 \\
\hline $8: 30$ & 17.5 & 19.6 \\
\hline $9: 30$ & 19.5 & 19.9 \\
\hline $10: 30$ & 19.9 & 20 \\
\hline $11: 30$ & 20.6 & 20.7 \\
\hline $12: 30$ & 21.2 & 21.8 \\
\hline $1: 30$ & 19.9 & 21.5 \\
\hline $2: 30$ & 17.1 & 20.6 \\
\hline $3: 30$ & 16.4 & 19.7 \\
\hline $4: 30$ & 16.1 & 18.6 \\
\hline $5: 30$ & 14.9 & 17.6 \\
\hline $6: 30$ & 13.8 & 16.9 \\
\hline
\end{tabular}

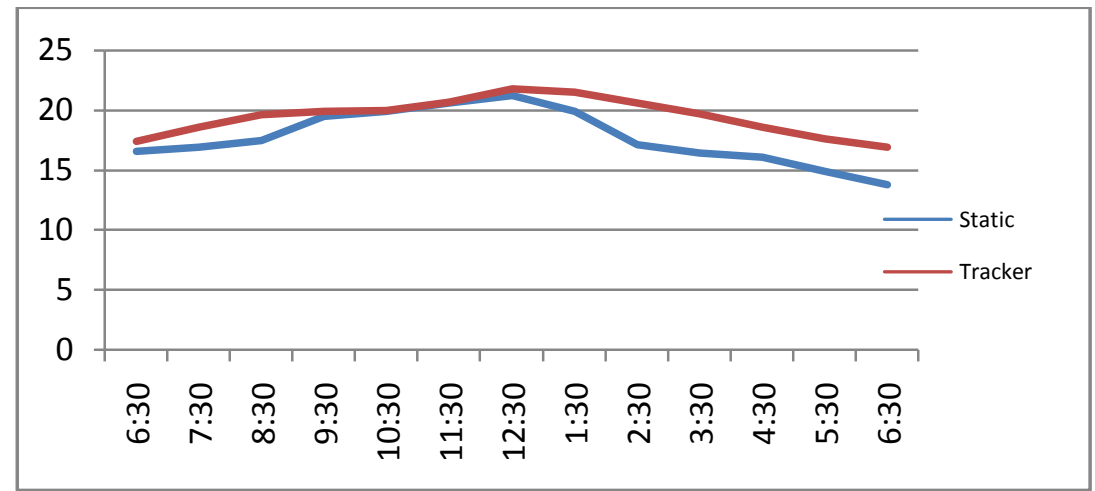

Fig 5: Result comparison of static panel and solar tracker.

\section{CONCLUSION}

A model of single axis solar tracker controlled by arduino microcontroller has been developed with integration of wind protection. The model tracks the sun direction in order to acquire maximum solar power at the output. The circuitry is made simple with minimum resources, ensuring efficiency. The above model can be installed in residential/domestic area for backup or alternative generation for low power applications or appliances.

\section{REFERENCES}

[1] Al-Naima F.M., Yaghobian N.A. "Design and construction of a solar tracking system", Solar Wind Technol. 1990; 7:611-617.

[2] Abdallah S., Nijmeh S. "Two axes sun tracking system with PLC control”, Energ. Convers. Manage. 2004; 45:1931-1939.

[3] Chen F., Feng J., Hong Z. "Digital sun sensor based on the optical vernier measuring principle”, Meas. Sci. Technol. 2006; 17:2494-2498.

[4] Grena R. "An algorithm for the computation of the solar position", Sol. Energy. 2008; 82:462-470.

[5] Chong K.K., Wong C.W. "General formula for on-axis sun tracking system and its application in improving tracking accuracy of solar collector”, Sol. Energ. 2009; 83:298-305.

[6] Reda I., Andreas A. "Solar position algorithm for solar radiation applications", Sol. Energ. 2004; 76:577-589.

[7] Chen F., Feng J. “Analogue sun sensor based on the optical nonlinear compensation measuring principle”, Meas. Sci. Technol. 2007; 18:2111-2115.

[8] Chen Y.T., Lim B.H., Lim C.S. "General sun tracking formula for heliostats with arbitrarily oriented axes”, J. Sol. Energ. Eng. 2006; 128:245-250.

[9] Chen Y.T., Chong K.K., Lim C.S. "Report of the first prototype of non-imaging focusing heliostat and its application in high temperature solar furnace", Sol. Energ. 2002; 72:531-544.

[10] Chong K.K., Siaw F.L., Wong C.W., Wong G.S. "Design and construction of non-imaging planar concentrator for concentrator photovoltaic system", Renewab. Energ. 2009; 34:1364-1370.

[11] WeiboLiu,"SunTracker: Design, Build \& Test", IEEE 2015.

[12] Sathyanarayana P, Rajkiranallal, Lakshmi Sagar P.S., Girish Kumar. "Effect of Shading on the Performance of Solar PV Panel”, 2015.

[13] Vukica M. Jovanovic, Michael Seek, Orlando Ayala, Sylvain Marsillac,"Single Axis Solar Tracker Actuator Location Analysis", IEEE2016.

[14] Chia Seet Chin, Prabhakaran Neelakantan, Soo Siang Yang, BihLii Chua, Kenneth Tze Kin Teo. "Effect of Partially Shaded Conditions on Photovoltaic Array's Maximum Power Point Tracking", 2008.

[15] Pawan Kumar Pandit, P.B.L Chaurasia. "Experimental Study of Shading Effect on PV Module and Improvement in Power Using Diode on series \& Parallel PV Module”, IJSR 2014. 